\title{
Aspergillus lentulus
}

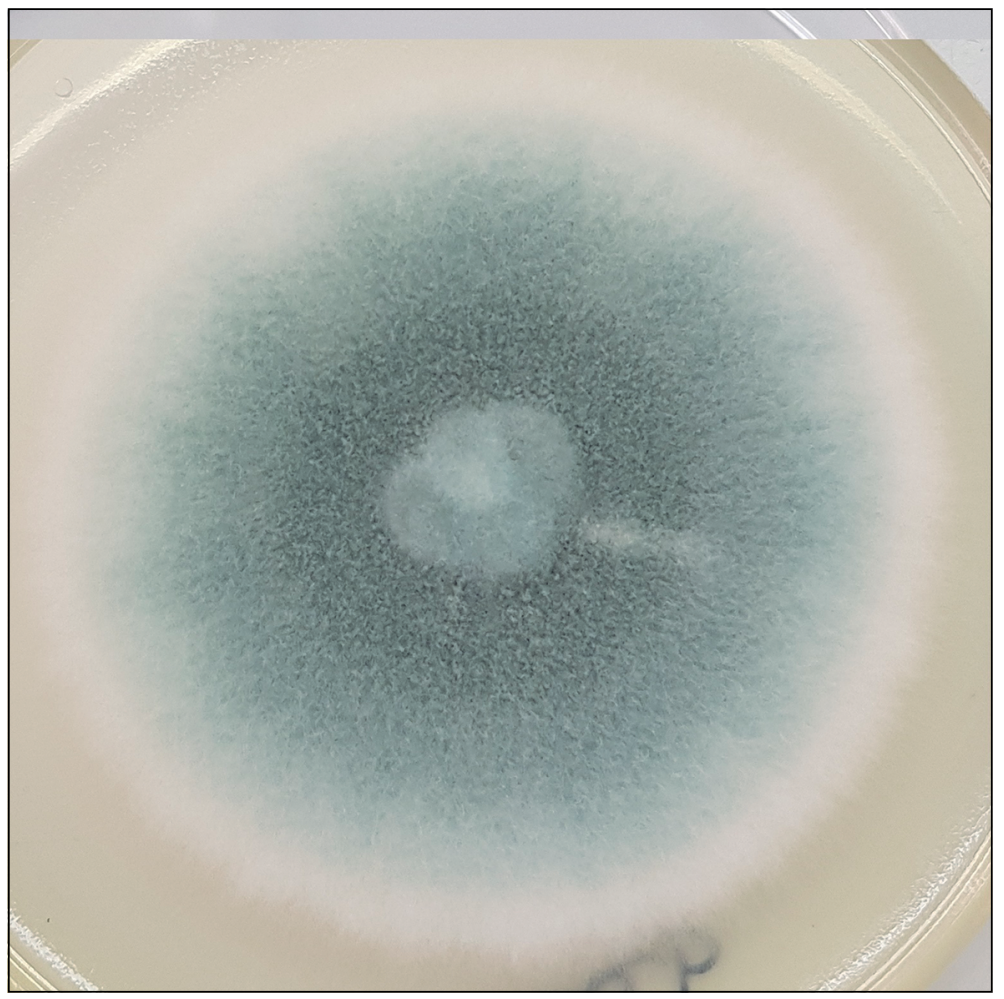

Figura 1. Colonia de Aspergillus lentulus, 5 días de crecimiento a $30^{\circ} \mathrm{C}$ en agar Sabouraud. Obsérvese el color azul-verdoso similar a colonias de $A$. fumigatus.

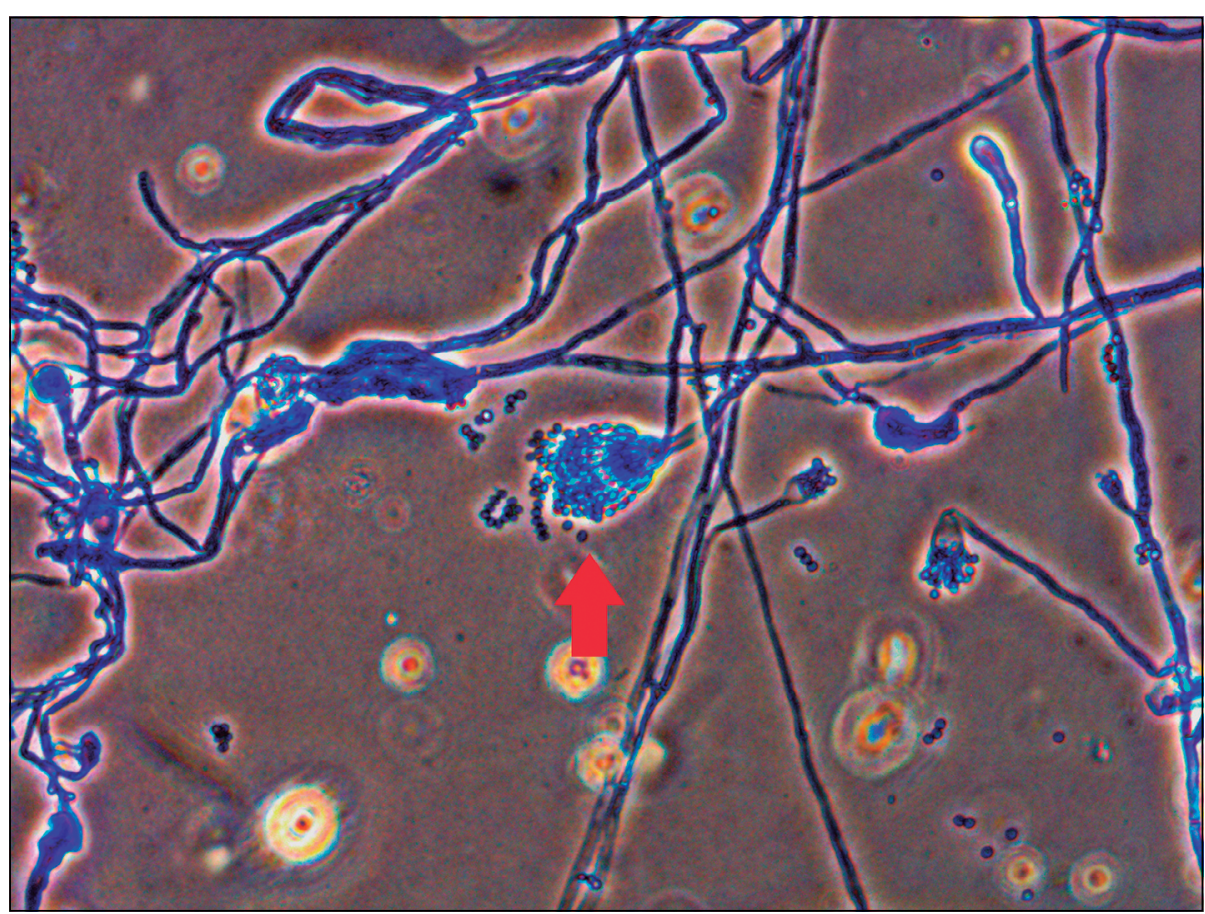

Figura 2. Cabeza aspergilar (flecha) de A. lentulus (azul de lactofenol X 40). 


\section{Aspergillus lentulus}

Aspergillus lentulus es un hongo filamentoso perteneciente a la sección Fumigati o fumigatus complex. Similar al resto de las especies de esta sección, A. lentulus se encuentra distribuido ampliamente en la naturaleza y se ha asociado principalmente a infecciones pulmonares. Se describió por primera vez en el año 2004; sin embargo, estudios retrospectivos, muestran su presencia en aislados clínicos previo a esta fecha, habiendo sido identificados inicialmente como $A$. fumigatus. Si bien A. lentulus presenta algunas características distintas de A. fumigatus, éstas son inespecíficas. Entre ellas destacan la formación de colonias más bien flocosas verde-grisáceas, con una coloración amarilla-café en el reverso. Microscópicamente se caracteriza por la escasa producción de conidias que, cuando están presentes, suelen ser globosas y de menor tamaño. De igual forma, esta especie no es capaz de crecer a más de $48^{\circ} \mathrm{C}$. Clínicamente $A$. lentulus se ha asociado principalmente a infecciones invasoras en receptores de trasplante de células madre hematopoyéticas y de órganos sólidos. La frecuencia de infecciones por $A$. lentulus representa menos de $2 \%$ de las infecciones causadas por A. sección Fumigati. Esta baja frecuencia se explicaría por la menor patogenicidad de este hongo dado, probablemente, por la menor termotolerancia y menor producción de micotoxinas. La correcta identificación a nivel de especie es importante, ya que se han descrito cepas de $A$. lentulus con CIM aumentadas tanto a los azoles como a equinocandinas y anfotericina B, con rangos de CIM que llegan a los $32 \mu \mathrm{g} / \mathrm{mL}$ para anfotericina B y $16 \mu \mathrm{g} / \mathrm{mL}$ para voriconazol. La identificación a nivel de especie puede realizarse mediante la secuenciación de los genes de la $\beta$-tubulina, calmodulina y/o actina. Por otro lado, la espectrometría de masas MALDI-TOF ha mostrado ser una herramienta útil para la diferenciación de especies crípticas de esta sección, con un $100 \%$ de sensibilidad para la detección de esta especie.

\section{Referencias bibliográficas}

1.- Balajee S A, Weaver A M, Imhof A, Gribskov J, Marr K A. Aspergillus fumigatus variant with decreased susceptibility to multiple antifungals. Antimicrob Agents Chemother 2004; 48: 1197-203. doi: 10.1128/AAC.48.4.1197-1203.

2.- Balajee S A, Gribskov J L, Hanley E, Nickle D, Marr K A. Aspergillus lentulus sp. nov., a new sibling species of $A$. fumigatus. Eukaryot Cell 2005; 3: 625-32. doi: 10.1128/EC.4.3.625-632.2005.

3.- Verwer P E, van Leeuwen W B, Girard V, Monnin V, van Belkum A, Staab J F, et al. Discrimination of Aspergillus lentulus from Aspergillus fumigatus by Raman spectroscopy and MALDI-TOF MS. Eur J Clin Microbiol Infect Dis 2014; 33: 245-51. doi: 10.1007/ s10096-013-1951-4.

4.- Alastruey-Izquierdo A, Alcazar-Fuoli L, Cuenca-Estrella M. Antifungal susceptibility profile of cryptic species of Aspergillus. Mycopathologia 2014; 178: 427-33. doi: 10.1007/s11046-014-9775-z. 